\title{
Precipitation dominates fire occurrence in Greece (1900-2010): its dual role in fuel build-up and dryness
}

\author{
F. Xystrakis ${ }^{1}$, A. S. Kallimanis ${ }^{1}$, P. Dimopoulos ${ }^{1}$, J. M. Halley ${ }^{2}$, and N. Koutsias ${ }^{1}$ \\ ${ }^{1}$ Department of Environmental and Natural Resources Management, University of Ioannina, G. Seferi 2, \\ 30100 Agrinio, Greece \\ ${ }^{2}$ Department of Biological Applications and Technology, University of Ioannina, 45110 Ioannina, Greece \\ Correspondence to: N. Koutsias (nkoutsia@cc.uoi.gr)
}

Received: 6 February 2013 - Published in Nat. Hazards Earth Syst. Sci. Discuss.: 26 March 2013

Revised: - Accepted: 21 November 2013 - Published: 3 January 2014

\begin{abstract}
Historical fire records and meteorological observations spanning over one century (1894-2010) were assembled in a database to collect long-term fire and weather data in Greece. Positive/negative events of fire occurrence on an annual basis were considered as the years where the annual values of the examined parameters were above (positive values) or below (negative values) the $95 \%$ confidence limits around the trend line of the corresponding parameter. To analyse the association of positive/negative events of fire occurrence with meteorological extremes, we proceeded with a cross-tabulation analysis based on a Monte Carlo randomization.

Positive/negative values of total annual precipitation were randomly associated with the corresponding values of burned areas, and significant associations were observed for seasonal precipitation totals (spring and fire season). Fire season precipitation is the dominant factor coinciding with negative values of area burned, while years with high spring precipitation coincide with years with large areas burned. These results demonstrate the dual role of precipitation in controlling a fire's extent through fuel build-up and dryness. Additionally, there is a clear outperformance of precipitation-related variables compared with temperature-related weather revealing that, at least in Greece, total area burned at the national scale is controlled by precipitation totals rather than air temperature.

This analysis improves our understanding of the underlying mechanisms of fire regimes and provides valuable information concerning the development of models relating fire activity to weather parameters, which are essential when facing a changing climate that may be associated with shifts
\end{abstract}

in various aspects of the typical fire regimes of ecosystems. Our results may allow fire managers to more easily incorporate the effect of extreme weather conditions into longterm planning strategies. They contribute to the exploration of fire-climate relationships and may become more important if climate change scenarios are used to predict the occurrence of future extreme weather taking into consideration that climate change is discussed on the basis of changes of extremes rather than changes in means.

\section{Introduction}

Wildfires are considered as one of the major forces shaping Mediterranean landscape and controlling vegetation communities' succession and structure (Serra et al., 2008; Millington et al., 2009). Wildfires also contribute to the development of the pattern of vegetation succession, the rate of which largely depends on the prevailing plant traits (Mouillot et al., 2003). Fire frequency, seasonality, intensity and extent are variables that are more likely to control forest distribution (Foster et al., 1998) and reshape and form Mediterranean landscape patterns and the distribution of vegetation communities (Pausas and Vallejo, 1999; Lloret et al., 2003; Pausas et al., 2008). It is argued that the distribution of shrublands in Mediterranean ecosystems does not solely depend on summer drought and winter precipitation patterns, but there can be a distinguished mosaic of fire-maintained and climatemaintained shrublands (Bond et al., 2005). This is because frequent and intense wildland fires tend to homogenize landscapes towards shrub-dominated cover types (Moreira et al., 
2011) and can restrict the regeneration potential of various plants, such as seeders, increasing the possibility of their distinction at landscape level (Lloret et al., 2003). Climate (along with soil features) controls primary productivity, which in turn determines fuel availability. Weather plays an important role in fire ignition and propagation (Vázquez et al., 2002).

The role of weather is complex and varies over spatiotemporal resolutions with short-term variation affecting local fire behaviour, and seasonal and inter-annual variations affecting fuel production and flammability over large areas as well as habitat type richness (Trouet et al., 2009; Falk et al., 2007; Drakou et al., 2011). The investigation of the role of either fuel or climate on the occurrence of large wildland fires has been mainly based on the assumption that these are either limited by (a) climate or (b) fuel accumulation (Meyn et al., 2007). In biomass-poor/seasonally dry ecosystems, large wildland fires are mainly limited by fuel quantity, and an above average moisture availability during the vegetation growth period at $\operatorname{lag}(0)$ or $\operatorname{lag}(t)$ increases the possibility of wildland fire occurrence (Meyn et al., 2007; Pausas, 2004). Moreover, various studies have shown that weather conditions are prime drivers of large regional fires (Bowman et al., 2009) and a number of weather variables have been identified as being significantly correlated with annual area burned and number of fires (Good et al., 2008; Pausas, 2004; Littell et al., 2009). The relative importance of weather variables differs among different studies, but those most often examined are the length and intensity of dry spells (Beverly and Martell, 2005), various weather indices (Carvalho et al., 2008; Trouet et al., 2009) or simple weather variables such as mean air temperature and wind speed (Moritz et al., 2010; Flannigan et al., 2005). These findings can be combined into a generalized framework of synergy between weather and fuel (Koutsias et al., 2012), relating large fires with $\operatorname{lag}(0)$ weather features that are related to fuel moisture conditions (Jurdao et al., 2012; Chuvieco et al., 2009), providing suitable conditions for fire initiation and spread, and with $\operatorname{lag}(0)$ to $\operatorname{lag}(t)$ favourable moisture conditions during the vegetation growth period that increase fuel availability (Veblen et al., 2000; Zumbrunnen et al., 2009). It is fire season weather that triggers or restricts the fuel, landscape, topographic and socioeconomic variables in the expression of dominant factors of fire spread (Moreira et al., 2011; Bradstock, 2010).

Concerning extreme large fire events, it has been demonstrated that extreme weather results in large and intense fires (Beverly and Martell, 2005) and that the area burned progressively increases with extreme weather variables (Bessie and Johnson, 1995; Moritz et al., 2010). Moreover, under extreme weather conditions, modelling approaches predict that stands will exhibit crown fires regardless of their fuel conditions (Bessie and Johnson, 1995). Weather is tightly related to large and intense fires at least in boreal (Hély et al., 2001) and temperate ecosystems (Gedalof et al., 2005). Similar results have been also reported for Mediterranean-type ecosystems, where extreme weather becomes an increasingly important forcing mechanism for large fires (Moritz, 1997) and area burned by large fires ( $>100 \mathrm{ha}$ ) is positively correlated with summer dryness and negatively correlated with summer wetness (Ganteaume and Jappiot, 2013). Weather extremes at the 90th percentile have been identified as important variables when modelling number of fires and burned area (Carvalho et al., 2008). Striking examples are the extensive fires in Greece during the exceptionally hot and dry summer of 2007 (Founda and Giannakopoulos, 2009), when an area of 190836 ha was burned and 67 people died (Koutsias et al., 2012); the extreme fire events during the 2003 summer drought in Europe (European Commission, 2004); the extreme 1994 fires in Spain where an extremely large burned area (430 $000 \mathrm{ha}$ ) was associated with extreme values of meteorological variables (Piñol et al., 1998); and the extreme drought and high winds that were primarily responsible for the extensive area burned during 1988 in Yellowstone National Park, USA (Turner et al., 2003).

Although a thorough analysis of fire history patterns and their correlation with climate should include additional fire regime components such as socioeconomic factors and related land-use land-cover changes (Piñol et al., 1998; Serra et al., 2008; Ganteaume and Jappiot, 2013), an important part of variability in total burned area can be attributed to interannual climatic variability (Pausas, 2004; Moritz, 1997). Weather is considered more important than fuel in fire behaviour, and extreme weather-related variables outperform fuel-related variables in the explanation of variance in fire intensity of various types of conifer forests (Bessie and Johnson, 1995) or shrublands (Baeza et al., 2002), at least in homogenous landscapes or when fire frequency is low (Hély et al., 2001).

In this paper we analyse the relationships between weather and fire by examining whether years with values of area burned exceeding the $95 \%$ confidence intervals (upper and lower) of the estimated trend line coincide with respective observations above or below the $95 \%$ confidence intervals of various weather variables. This analysis aims to improve our understanding of the underlying mechanisms behind fire regimes and provides valuable information concerning the development of models relating fire activity to weather parameters (Moriondo et al., 2006). Such models are essential when facing a changing climate that may be associated with shifts in various aspects of the typical fire regimes of ecosystems. These shifts include the increase in length of seasons with fire risk as a result of increasing fire weather extremes (Moriondo et al., 2006) or the "movement" of fires towards non-fire-prone ecosystems of higher elevations (Koutsias et al., 2012). This is of major importance in Greece, a fire-prone Mediterranean country where such analyses are presently lacking or are abstract and that, according to data on the average area burned per fire, has the most severe forest fire problems of the European Union countries (Moriondo et al., 2006). 


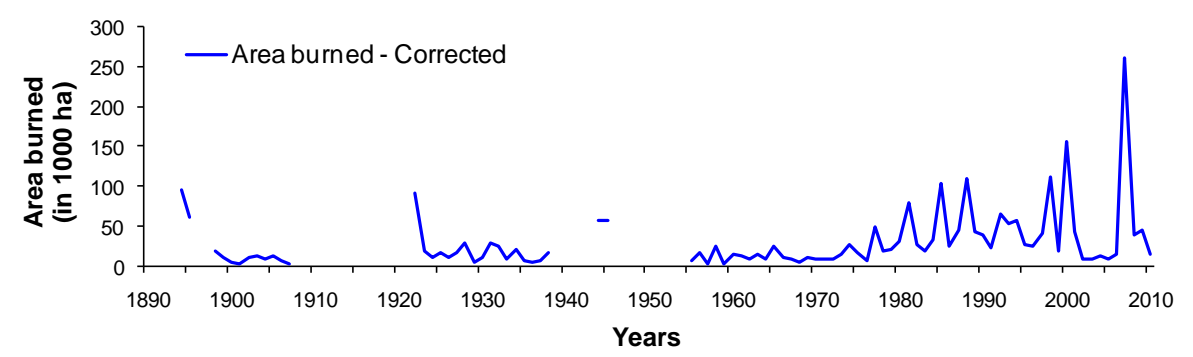

Fig. 1. Historical time series of area burned in Greece from 1894 to 2010 . Area burned is corrected on the basis of country's surface as described in the methods section.

\section{Materials and methods}

\subsection{Wildfire time-series data}

Statistics on the total yearly area burned at national level were gathered from different fire data providers including the National Statistical Service of Greece (NSSG), the Hellenic Forest Service (HFS), the Hellenic Fire Brigade (HFB), and Kailidis and Karanikola (2004). These data were then assembled in a long-term time series extending back to 1894 (Fig. 1). Two data gaps, the first during the period 1908-1921 and the second during that of 1939-1954 (excluding 1945, when some observations were taken), and two missing years in 1896 and 1897, are responsible for the breaks in the time series, which, as result, covers 86 of the 117 years between 1894 and 2010.

Since the total annual area burned from 1894 to 1912 referred to the country's surface area during that period in history $\left(63211 \mathrm{~km}^{2}\right)$, these values were adjusted to the country's current surface area $\left(132000 \mathrm{~km}^{2}\right)$ by multiplying by $2.088\left(=132000 \mathrm{~km}^{2} / 63211 \mathrm{~km}^{2}\right)$ so that the values of total area burned could be directly comparable throughout the examined period.

\subsection{Meteorological time-series data}

Time series of meteorological data extending to the end of the 19th century were acquired from the historical meteorological station of the National Observatory of Athens (NOA). The mean, mean minimum, mean maximum, absolute minimum and absolute maximum air temperature, as well as precipitation totals, were provided originally on a monthly basis for the period 1897-2010. The monthly precipitation values were then aggregated to seasonal values and to fire season (July-September) for the statistical analyses performed here (Fig. 2).

\subsection{Statistical analyses}

From the time-series data of both fire occurrence observations and meteorological parameters, we estimated the trend lines and the $95 \%$ confidence intervals of the model around the trend line. The variable "area burned" was $\ln$ transformed in order to reduce the effect of some very large values in the analyses. The linear regression model was then applied to the transformed values. Years during which the values of the examined variables were above the $95 \%$ confidence limits of the trend line were marked as "strongly positive values" (denoted by " +1 "), while years during which the values of the examined variables were below the $95 \%$ confidence limits of the trend line were marked as "strongly negative values" (denoted by "-1"). Finally, years during which the values of the examined variables fell within the $95 \%$ confidence limits were considered "close-to-predicted values" (denoted by "0"). Although this classification does not reveal the extreme values sensu stricto, it does allow for the cross-comparison of highly influential values of fire occurrence and meteorological variables.

To analyse how the positive or negative values of area burned and meteorological parameters coincide in time on an annual basis, we performed a cross-tabulation analysis within the time window between 1990 and 2010 in which 81 cases (years) are observed after excluding the missing years from both time series. Additionally, we used a Monte Carlo randomization test to examine whether the observed frequencies were statistically different from random coincidence. In each year, and for each variable, we randomly assigned one of the three values $(1,0,-1)$, keeping the frequency distribution of each variable constant. For each pair of variables we then measured the frequency of each combination of values $(-1-1,-10,-11,0-1,00,01,1-1,10,11)$. This process was repeated 1000 times. Finally, for each pair of variables we compared the observed frequency of each combination with the results of the 1000 randomizations.

\section{Results}

\subsection{Assessment of the extremes}

Figure 3 shows the time-series data of total burned area (ln transformation) together with the model fitted to the timeseries observations and the $95 \%$ confidence intervals of the model around the trend line. The strongly positive $(+1)$ or strongly negative $(-1)$ values, as well as close-to-predicted 

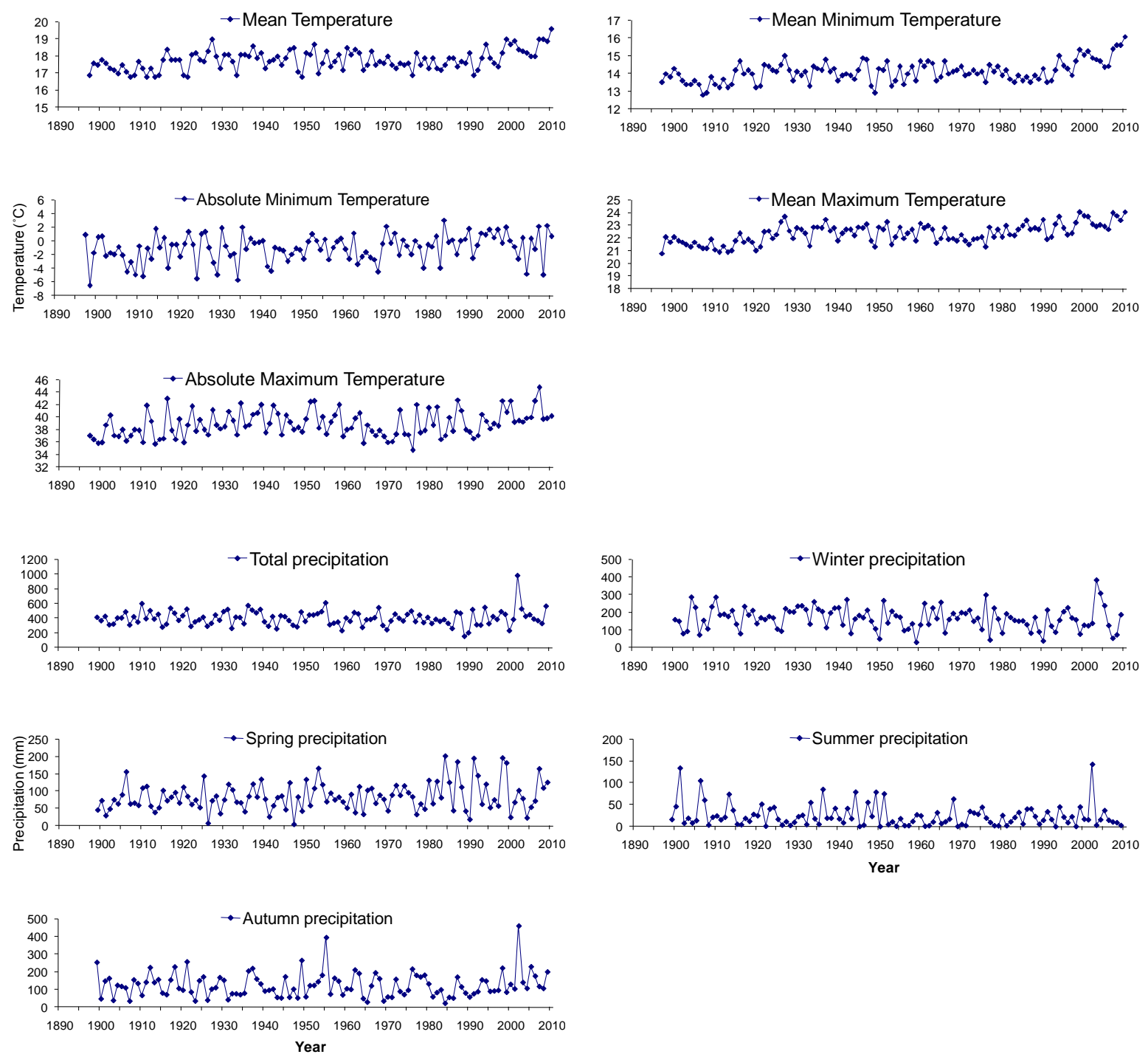

Fig. 2. Time series of historical temperature and precipitation data as acquired from the National Observatory of Athens (NOA).

values, within the $95 \%$ confidence intervals (0) are also depicted in Fig. 3. Of the 81 years considered in the analysis (only those with full data), 30 strongly positive, 34 strongly negative and 17 close-to-predicted values were recorded. It is worth noting that of the 30 positive values of area burned, 19 were observed after 1974.

Figure 4 shows the time-series data of selected meteorological parameters concerning air temperature (absolute maximum, mean maximum and mean air temperature) together with the linear model fitted to the time-series observations and the $95 \%$ confidence intervals of the model around the trend line for each parameter. Of the $81 \mathrm{yr}$ analysed, 36 strongly negative, 28 strongly positive and 17 close-topredicted values of absolute maximum air temperature were recorded. For mean maximum air temperature, 27 strongly negative, 36 strongly positive and 18 close-to-predicted values were observed, while for the mean air temperature, 34 strongly negative, 32 strongly positive and 15 closeto-predicted values were observed. During the last $15 \mathrm{yr}$, only one negative value of temperature-related variables was recorded, that being the mean maximum air temperature of 2006 (Fig. 4). In contrast, during the same period, several years are above the $95 \%$ confidence interval.

Figure 4 shows the time-series data of selected precipitation-related variables (total, spring and fire season's precipitation) together with the line fitted to the time-series observations and the $95 \%$ the trend line for each variable. Of the $81 \mathrm{yr}$ studied, 35 strongly positive, 26 strongly negative and 20 close-to-predicted values were observed for the total precipitation. For fire season precipitation, 43 strongly negative, 18 strongly positive and 20 close-to-predicted values were observed. Finally, for spring precipitation, 37 strongly 


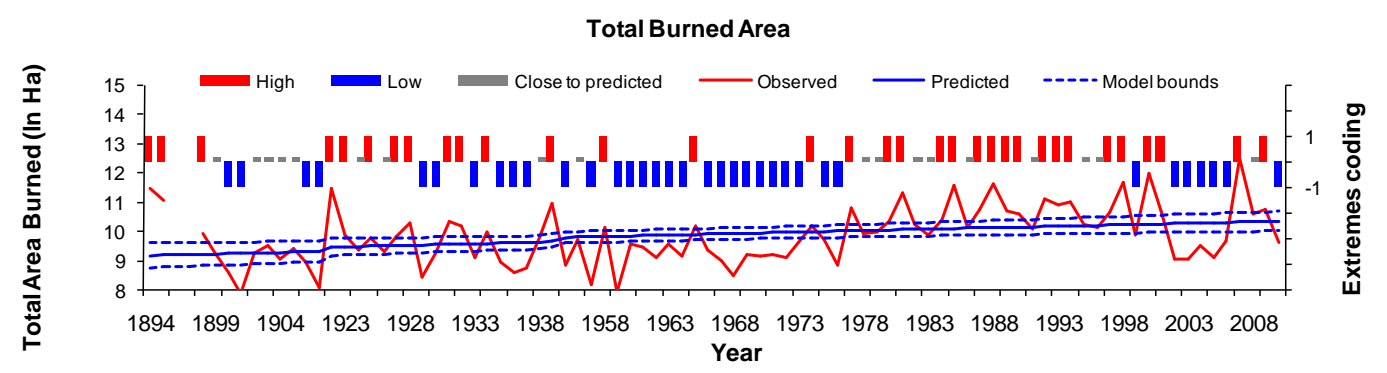

Fig. 3. Trend lines and the $95 \%$ confidence intervals of the trend line of fire occurrence statistics (burned area). These are used as bounds to define strongly positive (red columns), strongly negative (blue columns) and close-to-predicted (grey columns) values of fire occurrence.

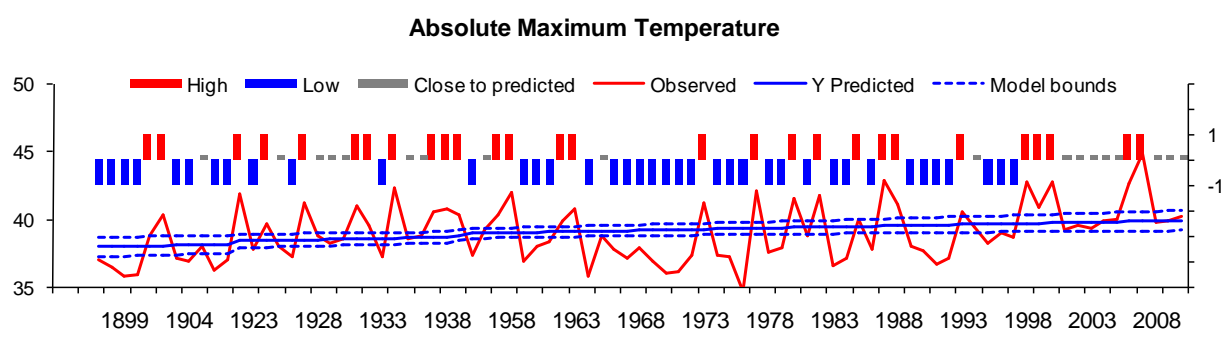

Mean Maximum Temperature

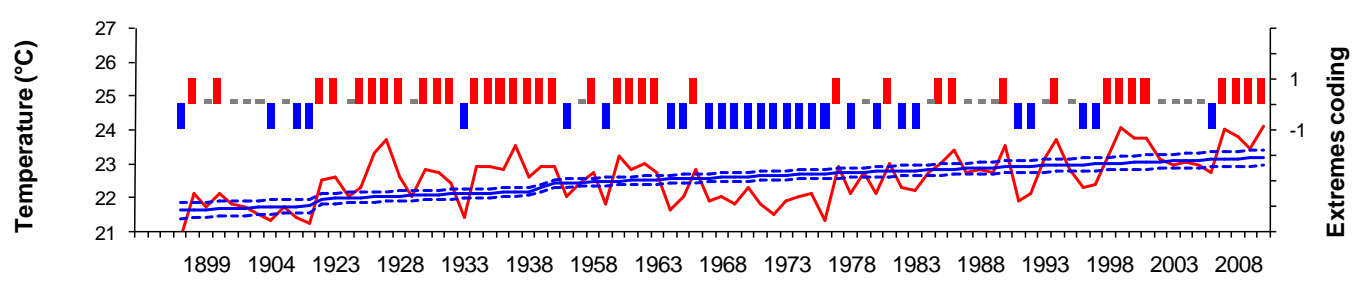

Mean Temperature

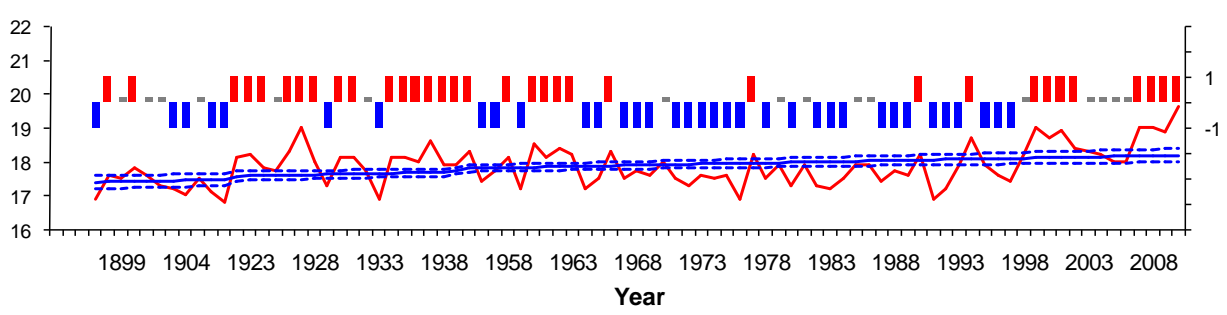

Fig. 4. Trend lines and the $95 \%$ confidence intervals of the model around the trend line of air-temperature-related meteorological parameters (absolute maximum, mean maximum and mean air temperature). These are used as bounds to define strongly positive (red columns), strongly negative (blue columns) and close-to-predicted (grey columns) values of fire occurrence.

negative, 25 strongly positive and 19 close-to-predicted values were observed. Unlike air temperature, strongly positive and negative values of total and spring precipitation are evenly distributed within the time window. However, regarding fire season precipitation, there is one period between 1979 and 1998 where no strongly positive values are observed. Additionally, the summer of 2002 was exceptionally wet.

\subsection{Cross-tabulation analysis}

The results of the cross-tabulation analysis together with the Monte Carlo randomization test are summarized in Tables 16.

The cross-tabulation analysis shows that of the 30 strongly positive values of area burned, $16(53.33 \%)$ coincide with strongly positive values of absolute maximum air 


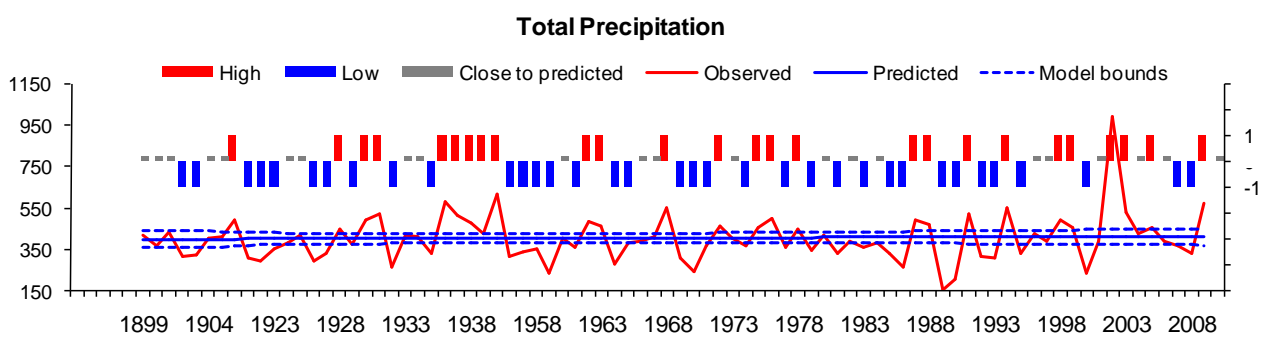

Fire Season's Precipitation

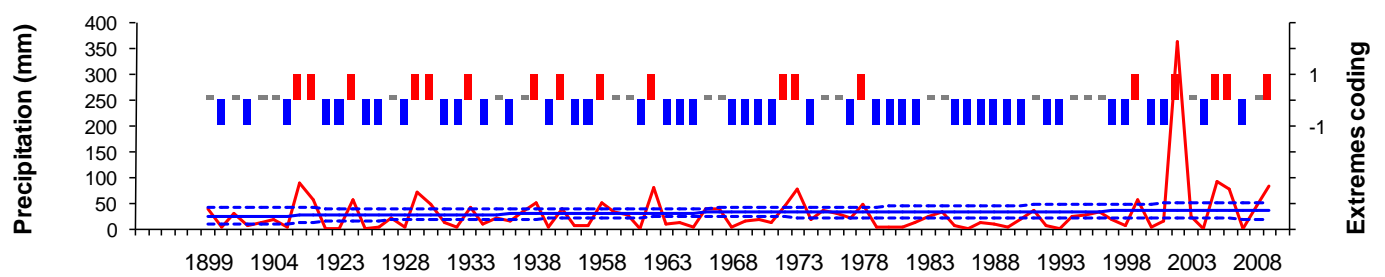

Spring Precipitation

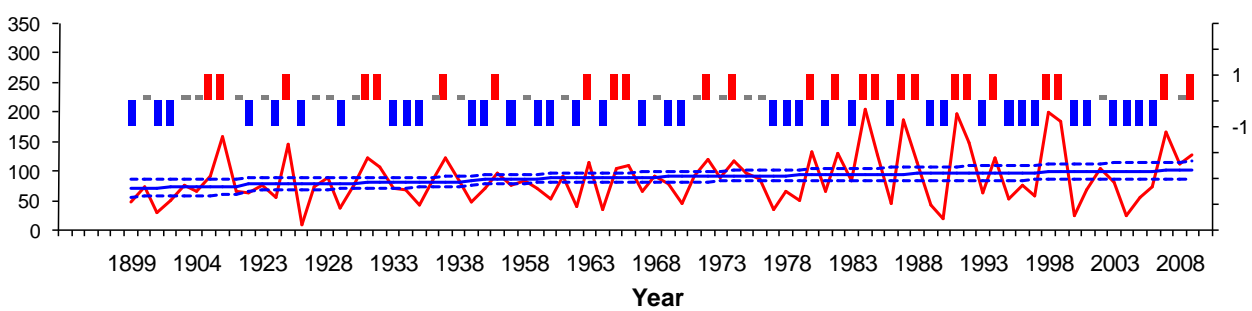

Fig. 5. Trend lines and the $95 \%$ confidence intervals of the model around the trend line of precipitation-related meteorological parameters (total, spring and fire season precipitation). These are used as bounds to define strongly positive (red columns), strongly negative (blue columns) and close-to-predicted (grey columns) values of fire occurrence.

temperature. On the other hand, of the 28 strongly positive values of absolute maximum air temperature, $16(57.14 \%)$ coincide with strongly positive values of area burned. This means that the majority of strongly positive values of area burned were also years with strongly positive values of absolute maximum air temperature and vice versa. Additionally, it can be argued that strongly positive values of area burned are limited by absolute maximum air temperature since strongly negative values of the latter result in significantly fewer positive values of area burned (22.22\%) than those expected under a random process according to the Monte Carlo randomization test.

Similar results were recorded for mean maximum air temperature. Of the 30 strongly positive values of area burned, $20(66.67 \%)$ correspond to strongly positive values of mean maximum air temperature. Analogously, of the 36 strongly positive values of mean maximum air temperature, $20(55.56 \%)$ coincide with strongly positive values of area burned. The above-mentioned indicates that years of extensive burned areas strongly correspond to years of high mean maximum air temperature and vice versa, years with high mean maximum air temperature are expected to coincide with years of increased burned area. Similarly, years with strongly negative values of mean maximum air temperature result in significantly fewer strongly positive values of burned area than those expected under a random process according to the Monte Carlo randomization test, thus indicating an inverse relationship between low mean maximum air temperature and extensive area burned.

The cross-tabulation of the strongly positive and negative values of area burned against the respective values of mean air temperature did not reveal any statistical significant differences compared to random coincidence based on the Monte Carlo randomization test.

Concerning precipitation-related variables, of the 30 strongly positive values of area burned, $8(26.67 \%)$ coincide with strongly positive and $16(53.33 \%)$ with strongly negative values of total annual precipitation. Yet these frequencies do not differ significantly from random coincidence. 
Table 1. Cross-tabulation results between burned area and absolute maximum air temperature. Monte Carlo randomization confidence limits are in parentheses. Values in bold are statistically significant.

\begin{tabular}{|c|c|c|c|c|c|c|c|c|c|}
\hline \multicolumn{10}{|c|}{ Total Area Burned } \\
\hline \multirow{8}{*}{ 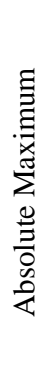 } & \multirow{8}{*}{ 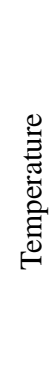 } & & -1 & 0 & 1 & Sum & -1 & 0 & 1 \\
\hline & & -1 & $18(11-19)$ & $10(4-11)$ & $8(9-18)$ & 36 & $50.00 \%$ & $27.78 \%$ & $22.22 \%$ \\
\hline & & 0 & $8(4-11)$ & $3(1-6)$ & $6(3-10)$ & 17 & $47.06 \%$ & $17.65 \%$ & $35.29 \%$ \\
\hline & & 1 & $8(8-16)$ & $4(3-9)$ & $16(6-15)$ & 28 & $28.57 \%$ & $14.29 \%$ & $57.14 \%$ \\
\hline & & Sum & 34 & 17 & 30 & 81 & $41.98 \%$ & $20.99 \%$ & $37.04 \%$ \\
\hline & & -1 & $52.94 \%$ & $58.82 \%$ & $26.67 \%$ & $44.44 \%$ & & & \\
\hline & & 0 & $23.53 \%$ & $17.65 \%$ & $20.00 \%$ & $20.99 \%$ & & & \\
\hline & & 1 & $23.53 \%$ & $23.53 \%$ & $53.33 \%$ & $34.57 \%$ & & & \\
\hline
\end{tabular}

Table 2. Cross-tabulation results between burned area and mean maximum air temperature. Monte Carlo randomization confidence limits are noted in parentheses. Values in bold are statistically significant.

\begin{tabular}{|c|c|c|c|c|c|c|c|c|c|}
\hline \multicolumn{10}{|c|}{ Total Area Burned } \\
\hline \multirow{8}{*}{ 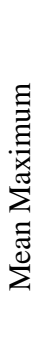 } & \multirow{8}{*}{ 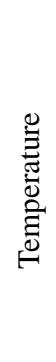 } & & -1 & 0 & 1 & Sum & -1 & 0 & 1 \\
\hline & & -1 & $15(7-15)$ & $7(2-9)$ & $5(6-14)$ & 27 & $55.56 \%$ & $25.93 \%$ & $18.52 \%$ \\
\hline & & 0 & $7(4-11)$ & $6(1-7)$ & $5(3-10)$ & 18 & $38.89 \%$ & $33.33 \%$ & $27.78 \%$ \\
\hline & & 1 & $12(11-19)$ & $4(4-11)$ & $20(9-18)$ & 36 & $33.33 \%$ & $11.11 \%$ & $55.56 \%$ \\
\hline & & Sum & 34 & 17 & 30 & 81 & $41.98 \%$ & $20.99 \%$ & $37.04 \%$ \\
\hline & & -1 & $44.12 \%$ & $41.18 \%$ & $16.67 \%$ & $33.33 \%$ & & & \\
\hline & & 0 & $20.59 \%$ & $35.29 \%$ & $16.67 \%$ & $22.22 \%$ & & & \\
\hline & & 1 & $35.29 \%$ & $23.53 \%$ & $66.67 \%$ & $44.44 \%$ & & & \\
\hline
\end{tabular}

The effect of fire season's precipitation was more interesting and provided argumentation in favour of its strong and straightforward association with the total annual area burned. Of the 30 strongly positive values of area burned, only $2(6.67 \%)$ coincide with strongly positive values of fire season's precipitation, while $25(83.33 \%)$ coincide with strongly negative values. However, of the 18 positive values of fire season precipitation, $13(72.22 \%)$ coincide with strongly negative and only $2(11.11 \%)$ coincide with strongly positive values of area burned. This means that, in the majority of cases $(83.33 \%)$, a year with increased area burned was also a year with low fire season precipitation. Additionally, years characterized by high fire season precipitation were unlikely to be characterized by extensive burned areas.

The effect of spring precipitation was also apparent but contradictive. Of the 30 strongly positive values of area burned, $15(50.00 \%)$ coincide with positive and $11(36.67 \%)$ with strongly negative values of spring precipitation. Of the 25 strongly positive values of spring precipitation, 15 $(60.00 \%)$ coincide with strongly positive and $6(24.00 \%)$ with strongly negative values of area burned.
The cross-tabulation of the strongly positive and negative values of area burned against autumn and winter precipitation did not show any significant patterns, while the patterns of summer precipitation resemble the outputs of fire season precipitation since fire season includes the summer months. These outputs were chosen not to be shown in the paper due to size restrictions.

\section{Discussion}

Of the 30 years recorded with strongly positive values of burned area, 19 of these were observed after 1974. This period (1974-2010) commences in 1974, when the country's seven-year dictatorship ended and the third Hellenic democratic period began. As noted by Koutsias et al. (2013), the development of Greece in this period brought significant socioeconomic changes (an increase in personal income, rural abandonment and urbanization, development of wildlandurban interface areas, etc.). Therefore, the occurrence of most years with large burned areas is linked with, among other factors, increased fuel accumulation by land abandonment and afforestation of former agricultural land (Pausas and Fernández-Muñoz, 2012). A general increasing trend in area burned in Greece during the last decades was also reported 
Table 3. Cross-tabulation results between area burned area and mean air temperature. The Monte Carlo randomization confidence limits are in parentheses.

\begin{tabular}{|c|c|c|c|c|c|c|c|c|}
\hline & & & & Tot & Area Bur & & & \\
\hline & & -1 & 0 & 1 & Sum & -1 & 0 & 1 \\
\hline$\cong$ & -1 & $15(10-19)$ & $9(4-11)$ & $10(8-17)$ & 34 & $44.12 \%$ & $26.47 \%$ & $29.41 \%$ \\
\hline 䲶 & 0 & $6(3-10)$ & $4(1-6)$ & $5(2-9)$ & 15 & $40.00 \%$ & $26.67 \%$ & $33.33 \%$ \\
\hline పัँ & 1 & $13(9-17)$ & $4(3-10)$ & $15(8-16)$ & 32 & $40.63 \%$ & $12.50 \%$ & $46.88 \%$ \\
\hline$\stackrel{\bar{\omega}}{\oplus}$ & Sum & 34 & 17 & 30 & 81 & $41.98 \%$ & $20.99 \%$ & $37.04 \%$ \\
\hline$\stackrel{\Xi}{ٍ ్ ల ~}$ & -1 & $44.12 \%$ & $52.94 \%$ & $33.33 \%$ & $41.98 \%$ & & & \\
\hline$\Sigma$ & 0 & $17.65 \%$ & $23.53 \%$ & $16.67 \%$ & $18.52 \%$ & & & \\
\hline & 1 & $38.24 \%$ & $23.53 \%$ & $50.00 \%$ & $39.51 \%$ & & & \\
\hline
\end{tabular}

Table 4. Cross-tabulation results between area burned and total annual precipitation. The Monte Carlo randomization confidence limits are in parentheses.

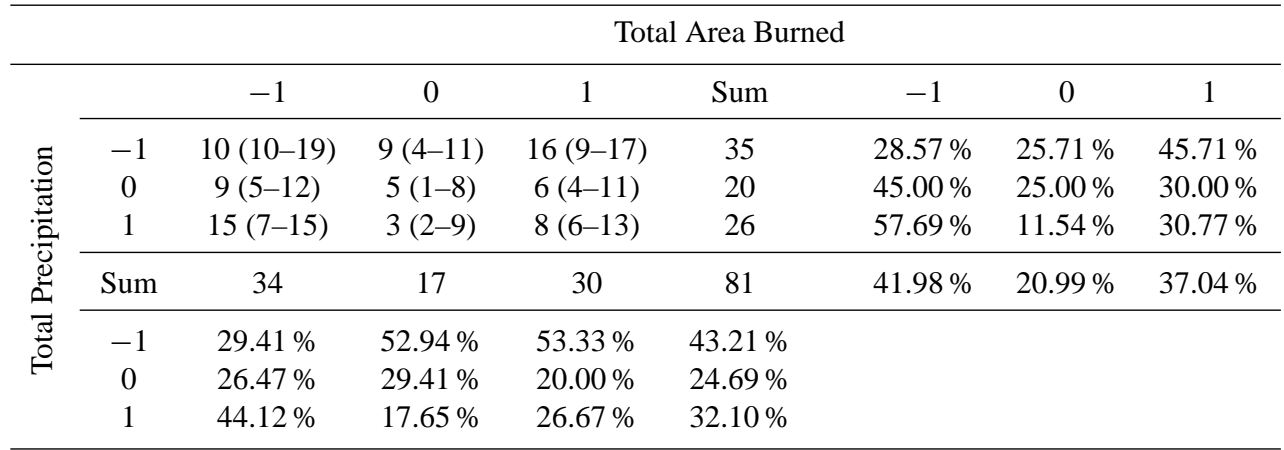

by Dimitrakopoulos et al. (2011b) and Koutsias et al. (2013), although no significant trend was found in the total annual burned area during the period 1974-2010 (Koutsias et al., 2013).

Concerning the meteorological parameters, fire season precipitation is the dominant factor coinciding with area burned. The tight relation between fire season precipitation and area burned is also revealed in similar studies, as for example in Portugal (Viegas and Viegas, 1994), Spain (Pausas, 2004), the western United States (Westerling et al., 2003) and Greece (Dimitrakopoulos et al., 2011b). Although strongly positive or negative values of total annual precipitation are randomly cross-tabulated with strongly positive or negative values of area burned, significant cross tabulations appear when seasonal precipitation totals (spring and fire season) are considered. The coincidence of positive values of summer precipitation with negative values of area burned stand as an indication of the direct effect of enhanced precipitation in fuel wetness, which in turn controls ignition probability (Jurdao et al., 2012) and can be used to predict periods of large burned areas (Chuvieco et al., 2009). The significant coincidence of positive values of spring precipitation with strongly positive values of area burned is probably associated with fuel build-up resulting from wet conditions during the growth season. In Mediterranean ecosystems, biological activity is primarily controlled by water input (Lázaro et al., 2001) and the annual net ecosystem productivity is highly dependant on spring precipitation but less so on that of summer (Allard et al., 2008). To summarize, the observed pattern of cross-tabulations of annual area burned against fire season and spring precipitation totals stands as a strong indication that, on the one hand, increased antecedent spring precipitation reflects a positive association with annual area burned due to fuel build-up, while, on the other hand, increased fire season precipitation is negatively correlated with area burned due to wet conditions during the fire season, a finding similar to those of Littell et al. (2009) and Koutsias et al. (2013). Seasonal precipitation assists in controlling the counterbalance effects that precipitation during different seasons has on fire extent, while annual aggregation could obscure such significant associations. A similar argument can be supported for the air temperature variables. Mean air temperature does not reflect any significant deviation from randomness in cross-tabulation because this variable is highly dependent on winter months. On the other hand, mean maximum and absolute maximum air temperature are variables dominated by summer-period values; therefore their significant 
Table 5. Cross-tabulation results between area burned and fire season precipitation. The Monte Carlo randomization confidence limits are in parentheses. Values in bold are statistically significant.

\begin{tabular}{|c|c|c|c|c|c|c|c|c|c|}
\hline \multicolumn{10}{|c|}{ Total Area Burned } \\
\hline \multirow{8}{*}{ 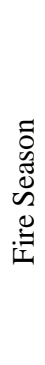 } & \multirow{8}{*}{ 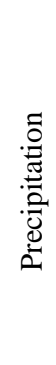 } & & -1 & 0 & 1 & Sum & -1 & 0 & 1 \\
\hline & & -1 & $11(14-22)$ & $7(6-13)$ & $25(12-20)$ & 43 & $25.58 \%$ & $16.28 \%$ & $58.14 \%$ \\
\hline & & 0 & $10(5-12)$ & $7(1-7)$ & $3(4-11)$ & 20 & $50.00 \%$ & $35.00 \%$ & $15.00 \%$ \\
\hline & & 1 & $13(4-11)$ & $3(1-7)$ & $2(3-10)$ & 18 & $72.22 \%$ & $16.67 \%$ & $11.11 \%$ \\
\hline & & Sum & 34 & 17 & 30 & 81 & $41.98 \%$ & $20.99 \%$ & $37.04 \%$ \\
\hline & & -1 & $32.35 \%$ & $41.18 \%$ & $83.33 \%$ & $53.09 \%$ & & & \\
\hline & & 0 & $29.41 \%$ & $41.18 \%$ & $10.00 \%$ & $24.69 \%$ & & & \\
\hline & & 1 & $38.24 \%$ & $17.65 \%$ & $6.67 \%$ & $22.22 \%$ & & & \\
\hline
\end{tabular}

Table 6. Cross-tabulation results between the total area burned and spring precipitation. The Monte Carlo randomization confidence limits are noted in parentheses. Values in bold are statistically significant.

\begin{tabular}{|c|c|c|c|c|c|c|c|c|}
\hline & & \multicolumn{7}{|c|}{ Total Area Burned } \\
\hline \multirow{8}{*}{ 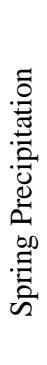 } & & -1 & 0 & 1 & Sum & -1 & 0 & 1 \\
\hline & -1 & $17(11-19)$ & $9(4-11)$ & $11(10-18)$ & 37 & $45.95 \%$ & $24.32 \%$ & $29.73 \%$ \\
\hline & 0 & $11(4-12)$ & $4(1-7)$ & $4(4-10)$ & 19 & $57.89 \%$ & $21.05 \%$ & $21.05 \%$ \\
\hline & 1 & $6(7-14)$ & $4(2-9)$ & $15(6-13)$ & 25 & $24.00 \%$ & $16.00 \%$ & $60.00 \%$ \\
\hline & Sum & 34 & 17 & 30 & 81 & $41.98 \%$ & $20.99 \%$ & $37.04 \%$ \\
\hline & -1 & $50.00 \%$ & $52.94 \%$ & $36.67 \%$ & $45.68 \%$ & & & \\
\hline & 0 & $32.35 \%$ & $23.53 \%$ & $13.33 \%$ & $23.46 \%$ & & & \\
\hline & 1 & $17.65 \%$ & $23.53 \%$ & $50.00 \%$ & $30.86 \%$ & & & \\
\hline
\end{tabular}

coincidence with area burned is an indirect indication of the effect of seasonal aggregation.

Additionally, there is a clear outperformance of precipitation-related variables compared to temperaturerelated weather ones. This outperformance reveals that, at least in Greece, extreme fires are controlled by precipitation rather than air temperature. This is contrary to the findings in other regions, where air temperature was among the most important fire drivers and conditionally outperformed precipitation variables (Turetsky et al., 2004; Vázquez and Moreno, 1993). However, similar to our results, maximum air temperature outperformed mean air temperature in correlating with area burned (Vázquez and Moreno, 1993). In Portugal, monthly means (mean and maximum) of the daily maximum air temperatures together with the mean fire weather index managed to summarize a fairly large part of the variation in annual area burned, while total precipitation did not enter the regression model (Carvalho et al., 2008). In Greece, it has been shown that precipitation is well correlated with area burned (Dimitrakopoulos et al., 2011b) and that air temperature has a low direct influence on extreme fire risk (Good et al., 2008). Yet Dimitrakopoulos et al. (2011a) showed that during the period 1990-2003, the vast majority of large wildfires occur during heat waves. However, although the research team considered air humidity (\%), they did not examine possible effects of precipitation totals.

There are various sources of uncertainty regarding the outputs of the present study. The high spatial variability of weather in Greece (Pnevmatikos and Katsoulis, 2006; Feidas et al., 2007) hampers the efforts to soundly describe inter-annual fluctuations from only the observations of a single weather station. Some variation in the area burned remains unexplained. Other weather parameters like wind speed (Moritz et al., 2010) or indices that combine a number of weather parameters (Camia and Amatulli, 2009) have been found to strongly correlate with area burned. In Greece though, it has been previously shown that the use of indices does not add significantly to explanation of variation (Xystrakis and Koutsias, 2013). Additionally, part of the unexplained variation should be attributed to other factors, besides weather, that have been found to contribute to fire spread. These factors include socioeconomic (Ganteaume and Jappiot, 2013) and landscape variables (Moreira et al., 2011). Nevertheless, it has to be pointed out that the long time series of both weather observations and fire statistics allows for the exploration of the revealed trends and correlations with an acceptable bias. 


\section{Conclusions}

A variety of meteorological parameters that could coincide with strongly positive or negative values of area burned are not considered in this paper. Additional information concerning air humidity or wind speed could help reveal further aspects of the correlation between fire and weather extremes (Dimitrakopoulos et al., 2011a); nevertheless, our results are comparable with other studies that discuss the effect of weather conditions on fire characteristics (Carvalho et al., 2008; Littell et al., 2009).

Our results could allow fire managers to more easily incorporate the effect of weather conditions into long-term planning strategies. They contribute to the exploration of fireclimate relationships and may become more important if climate change scenarios are used to predict the occurrence of future extreme weather (Trouet et al., 2009) since climate change is discussed on the basis of changes of extremes rather than changes in means (Field et al., 2012). Furthermore, most discussion on climate change is focused on the effect of increasing temperature trends, but our findings highlight the importance of precipitation and especially the need to predict changes in seasonal precipitation more accurately.

Acknowledgements. The research leading to these results has received funding from the European Union's Seventh Framework Programme (FP7/2007-2013) under grant agreement no. 243888 (FUME project). We acknowledge the National Observatory of Athens, Hellenic Forest Service and Hellenic Fire Brigade for providing data used in this study.

Edited by: R. Lasaponara

Reviewed by: four anonymous referees

\section{References}

Allard, V., Ourcival, J. M., Rambal, S., Joffre, R., and Rocheteau, A.: Seasonal and annual variation of carbon exchange in an evergreen Mediterranean forest in southern France, Glob. Change Biol., 14, 714-725, doi:10.1111/j.13652486.2008.01539.x, 2008.

Baeza, M. J., De Luis, M., Raventos, J., and Escarre, A.: Factors influencing fire behaviour in shrublands of different stand ages and the implications for using prescribed burning to reduce wildfire risk, J. Environ. Manage., 65, 199-208, doi:10.1006/jema.2002.0545, 2002.

Bessie, W. C. and Johnson, E. A.: The relative importance of fuels and weather on fire behavior in sub-alpine forests, Ecology, 76, 747-762, doi:10.2307/1939341, 1995.

Beverly, J. L. and Martell, D. L.: Characterizing extreme fire and weather events in the Boreal Shield ecozone of Ontario, Agr. Forest Meteorol., 133, 5-16, doi:10.1016/j.agrformet.2005.07.015, 2005.

Bond, W. J., Woodward, F. I., and Midgley, G. F.: The global distribution of ecosystems in a world without fire, New Phytol., 165, 525-537, doi:10.1111/j.1469-8137.2004.01252.x, 2005.
Bowman, D. M. J. S., Balch, J. K., Artaxo, P., Bond, W. J., Carlson, J. M., Cochrane, M. A., D’Antonio, C. M., DeFries, R. S., Doyle, J. C., Harrison, S. P., Johnston, F. H., Keeley, J. E., Krawchuk, M. A., Kull, C. A., Marston, J. B., Moritz, M. A., Prentice, I. C., Roos, C. I., Scott, A. C., Swetnam, T. W., van der Werf, G. R., and Pyne, S. J.: Fire in the Earth System, Science, 324, 481-484, doi:10.1126/science.1163886, 2009.

Bradstock, R. A.: A biogeographic model of fire regimes in Australia: current and future implications, Global Ecol. Biogeogr., 19, 145-158, doi:10.1111/j.1466-8238.2009.00512.x, 2010.

Camia, A. and Amatulli, G.: Weather factors and fire danger in the Mediterranean, in: Earth Observation of Wildland Fires in Mediterranean Ecosystems, edited by: Chuvieco, E., Springer Berlin Heidelberg, 71-82, 2009.

Carvalho, A., Flannigan, M. D., Logan, K., Miranda, A. I., and Borrego, C.: Fire activity in Portugal and its relationship to weather and the Canadian Fire Weather Index System, Int. J. Wildland Fire, 17, 328-338, doi:10.1071/Wf07014, 2008.

Chuvieco, E., González, I., Verdú, F., Aguado, I., and Yebra, M.: Prediction of fire occurrence from live fuel moisture content measurements in a Mediterranean ecosystem, Int. J. Wildland Fire, 18, 430-441, doi:10.1071/WF08020, 2009.

Dimitrakopoulos, A., Gogi, C., Stamatelos, G., and Mitsopoulos, I.: Statistical analysis of the fire environment of large forest fires (>1000 ha) in Greece, Pol. J. Environ. Stud., 20, 327-332, 2011a.

Dimitrakopoulos, A. P., Vlahou, M., Anagnostopoulou, C. G., and Mitsopoulos, I. D.: Impact of drought on wildland fires in Greece: implications of climatic change?, Climatic Change, 109, 331-347, doi:10.1007/s10584-011-0026-8, 2011 b.

Drakou, E., Kallimanis, A. S., Mazaris, A. D., Apostolopoulou, E., and Pantis, J. D.: Habitat type richness associations with environmental variables: a case study in the Greek Natura 2000 aquatic ecosystems, Biodivers. Conserv., 20, 929-943, 2011.

European Commission: Forest Fires in Europe, 2003 fire campaign, Official Publication of the European Commission, S.P.I.04.124, Italy, 51 pp., 2004.

Falk, D. A., Miller, C., McKenzie, D., and Black, A. E.: Cross-scale analysis of fire regimes, Ecosystems, 10, 809-823, doi:10.1007/s10021-007-9070-7, 2007.

Feidas, H., Noulopoulou, C., Makrogiannis, T., and Bora-Senta, E.: Trend analysis of precipitation time series in Greece and their relationship with circulation using surface and satellite data: $1955 \beta € 2001$, Theor. Appl. Climatol., 87, 155-177, 2007.

Field, C. B., Barros, V., Stocker, T .F., Qin, D., Dokken, D. J., Ebi, K. L., Mastrandrea, M. D., Mach, K. J., Plattner, G.-K., Allen, S. K., Tignor, M., and Midgley, P. M. (Eds.): Managing the Risks of Extreme Events and Disasters to Advance Climate Change Adaptation, A Special Report of Working Groups I and II of the Intergovernmental Panel on Climate Change, Cambridge University Press, Cambridge, UK and New York, 2012.

Flannigan, M. D., Logan, K. A., Amiro, B. D., Skinner, W. R., and Stocks, B. J.: Future area burned in Canada, Climatic Change, 72, 1-16, doi:10.1007/s10584-005-5935-y, 2005.

Foster, D. R., Knight, D. H., and Franklin, J. F.: Landscape patterns and legacies resulting from large, infrequent forest disturbances, Ecosystems, 1, 497-510, 1998.

Founda, D. and Giannakopoulos, C.: The exceptionally hot summer of 2007 in Athens, Greece - a typical summer in 
the future climate?, Global Planet. Change, 67, 227-236, doi:10.1016/j.gloplacha.2009.03.013, 2009.

Ganteaume, A. and Jappiot, M.: What causes large fires in Southern France, 294, 76-85, doi:10.1016/j.foreco.2012.06.055, 2012.

Ganteaume, A. and Jappiot, M.: What causes large fires in Southern France, Forest Ecol. Manage., 294, 76-85, doi:10.1016/j.foreco.2012.06.055, 2013.

Gedalof, Z., Peterson, D. L., and Mantua, N. J.: Atmospheric, climatic, and ecological controls on extreme wildfire years in the northwestern United States, Ecol. Appl., 15, 154-174, doi:10.1890/03-5116, 2005.

Good, P., Moriondo, M., Giannakopoulos, C., and Bindi, M.: The meteorological conditions associated with extreme fire risk in Italy and Greece: relevance to climate model studies, Int. J. Wildland Fire, 17, 155-165, doi:10.1071/WF07001, 2008.

Hély, C., Flannigan, M., Bergeron, Y., and McRae, D.: Role of vegetation and weather on fire behavior in the Canadian mixedwood boreal forest using two fire behavior prediction systems, Can. J. Forest Res., 31, 430-441, 2001.

Jurdao, S., Chuvieco, E., and Arevalillo, J. M.: Modelling fire ignition probability from satellite estimates of live fuel moisture content, Fir. Ecol., 8, 77-97, doi:10.4996/fireecology.0801077, 2012.

Kailidis, D. and Karanikola, P.: Forest Fires 1990-2000, Giachoudi Giapouli Editions, Thessalonikis, 434 pp., 2004.

Koutsias, N., Arianoutsou, M., Kallimanis, A. S., Mallinis, G., Halley, J. M., and Dimopoulos, P.: Where did the fires burn in Peloponnisos, Greece the summer of 2007? Evidence for a synergy of fuel and weather, Agr. Forest Meteorol., 156, 41-53, doi:10.1016/j.agrformet.2011.12.006, 2012.

Koutsias, N., Xanthopoulos, G., Founda, D., Xystrakis, F., Nioti, F., Pleniou, M., and Mallinis, G.: On the relationships between forest fires and weather conditions in Greece from longterm national observations (1894-2010), Int. J. Wildland Fire, doi:10.1071/WF12003, in press, 2013.

Lázaro, R., Rodrigo, F. S., Gutiérrez, L., Domingo, F., and Puigdefábregas, J.: Analysis of a 30-year rainfall record (1967-1997) in semi-arid SE Spain for implications on vegetation, J. Arid Environ., 48, 373-395, doi:10.1006/jare.2000.0755, 2001.

Littell, J. S., McKenzie, D., Peterson, D. L., and Westerling, A. L.: Climate and wildfire area burned in western U.S. ecoprovinces, 1916-2003, Ecol. Appl., 19, 1003-1021, 2009.

Lloret, F., Pausas, J. G., and Vila, M.: Responses of Mediterranean Plant Species to different fire frequencies in Garraf Natural Park (Catalonia, Spain): field observations and modelling predictions., Plant Ecol., 167, 223-235, doi:10.1023/A:1023911031155, 2003.

Meyn, A., White, P. S., Buhk, C., and Jentsch, A.: Environmental drivers of large, infrequent wildfires: the emerging conceptual model, Prog. Phys. Geog., 31, 287-312, doi:10.1177/0309133307079365, 2007.

Millington, J. D. A., Wainwright, J., Perry, G. L. W., RomeroCalcerrada, R., and Malamud, B. D.: Modelling Mediterranean landscape succession-disturbance dynamics: a landscape fire-succession model, Environ. Modell. Soft., 24, 1196-1208, doi:10.1016/j.envsoft.2009.03.013, 2009.

Moreira, F., Viedma, O., Arianoutsou, M., Curt, T., Koutsias, N., Rigolot, E., Barbati, A., Corona, P., Vaz, P., Xanthopoulos, G., Mouillot, F., and Bilgili, E.: Landscape - wild- fire interactions in southern Europe: implications for landscape management, J. Environ. Manage., 92, 2389-2402, doi:10.1016/j.jenvman.2011.06.028, 2011.

Moriondo, M., Good, P., Durao, R., Bindi, M., Giannakopoulos, C., and Corte-Real, J.: Potential impact of climate change on fire risk in the Mediterranean area, Clim. Res., 31, 85-95, doi:10.3354/cr031085, 2006.

Moritz, M. A.: Analyzing extreme disturbance events: fire in Los Padres National Forest, Ecol. Appl., 7, 1252-1262, 1997.

Moritz, M. A., Moody, T. J., Krawchuk, M. A., Hughes, M., and Hall, A.: Spatial variation in extreme winds predicts large wildfire locations in chaparral ecosystems, Geophys. Res. Lett., 37, L04801, doi:10.1029/2009g1041735, 2010.

Mouillot, F., Ratte, J. P., Joffre, R., Moreno, J. M., and Rambal, S.: Some determinants of the spatio-temporal fire cycle in a mediterranean landscape (Corsica, France), Landscape Ecol., 18, 665674, doi:10.1023/B:LAND.0000004182.22525.a9, 2003.

Pausas, J. G.: Changes in fire and climate in the eastern Iberian Peninsula (Mediterranean Basin), Climatic Change, 63, 337350, doi:10.1023/B:CLIM.0000018508.94901.9c, 2004.

Pausas, J. G. and Fernández-Muñoz, S.: Fire regime changes in the Western Mediterranean Basin: from fuel-limited to droughtdriven fire regime, Climatic Change, 110, 215-226, 2012.

Pausas, J. G. and Vallejo, V. R.: The role of fire in European Mediterranean ecosystems, in: Remote Sensing of Large Wildfires in the European Mediterranean Basin, edited by: Chuvieco, E., Springer-Verlag, 3-16, 1999.

Pausas, J. C., Llovet, J., Rodrigo, A., and Vallejo, R.: Are wildfires a disaster in the Mediterranean Basin? - a review, Int. J. Wildland Fire, 17, 713-723, doi:10.1071/Wf07151, 2008.

Piñol, J., Terradas, J., and Lloret, F.: Climate warming, wildfire hazard, and wildfire occurrence in coastal eastern Spain, Climatic Change, 38, 345-357, doi:10.1023/A:1005316632105, 1998.

Pnevmatikos, J. D. and Katsoulis, B. D.: The changing rainfall regime in Greece and its impact on climatological means, Meteorol. Appl., 13, 331-345, doi:10.1017/S1350482706002350, 2006.

Serra, P., Pons, X., and Sauri, D.: Land-cover and land-use change in a Mediterranean landscape: a spatial analysis of driving forces integrating biophysical and human factors, Appl. Geogr., 28, 189-209, doi:10.1016/j.apgeog.2008.02.001, 2008.

Trouet, V., Taylor, A., Carleton, A., and Skinner, C.: Interannual variations in fire weather, fire extent, and synoptic-scale circulation patterns in northern California and Oregon, Theor. Appl. Climatol., 95, 349-360, doi:10.1007/s00704-008-0012-x, 2009.

Turetsky, M. R., Amiro, B. D., Bosch, E., and Bhatti, J. S.: Historical burn area in western Canadian peatlands and its relationship to fire weather indices, Global Biogeochem. Cy., 18, 1-9, doi:10.1029/2004gb002222, 2004.

Turner, M. G., Romme, W. H., and Tinker, D. B.: Surprises and lessons from the 1988 Yellowstone fires, Front. Ecol. Environ., 1, 351-358, 2003.

Vázquez, A. and Moreno, J. M.: Sensitivity of fire occurrence to meteorological variables in Mediterranean and Atlantic areas of Spain, Landscape Urban Plan., 24, 129-142, 1993.

Vázquez, A., Pérez, B., Fernández-González, F., and Moreno, J. M.: Recent fire regime characteristics and potential natural vegetation relationships in Spain, J. Veg. Sci., 13, 663-676, doi:10.1111/j.1654-1103.2002.tb02094.x, 2002. 
Veblen, T. T., Kitzberger, T., and Donnegan, J.: Climatic and human influences on fire regimes in ponderosa pine forests in the Colorado Front Range, Ecol. Appl., 10, 1178-1195, 2000.

Viegas, D. X. and Viegas, M. T.: A relationship between rainfall and burned area for Portugal, Int. J. Wildland Fire, 4, 11-16, doi:10.1071/WF9940011, 1994.

Westerling, A. L., Gershunov, A., Brown, T. J., Cayan, D. R., and Dettinger, M. D.: Climate and wildfire in the western United States, B. Am. Meteorol. Soc., 84, 595-604, doi:10.1175/Bams84-5-595, 2003.
Xystrakis, F. and Koutsias, N.: Differences of fire activity and their underlying factors among vegetation formations in Greece, iForest - Biogeosci. Forest., 6, 132-140, doi:10.3832ifor0837-006, 2013.

Zumbrunnen, T., Bugmann, H., Conedera, M., and Burgi, M.: Linking forest fire regimes and climate - a historical analysis in a dry inner alpine valley, Ecosystems, 12, 73-86, doi:10.1007/s10021008-9207-3, 2009. 